\title{
Ensino de Computação: um relato de experiência no Ensino fundamental I
}

\author{
Mateus M. Carrascoso, Sabrina A. Rosa, Gabriel M. Cichoki, Keny T. Teixeira, \\ Rodrigo C. Thom de Souza, Selma dos Santos Rosa, Valdir Rosa
}

\author{
Universidade Federal do Paraná \\ \{mateusmorial, sabrinaanielly, cichoki, kenytonin, thom, \\ selmadossantos, valdirrosa\}eufpr.br
}

\begin{abstract}
This article is about an experience report, with qualitative bias and data collection through participant observation, about an intervention with 5th year elementary school children I. Basic knowledge about internet safety, ergonomics, hardware, software and accessibility, necessary for a correct and conscious use of this resource, were analyzed. The results pointed to the importance of students thinking, discovering, articulating theories and practices, interpreting, analyzing and explaining in words like learning about and with computers, in a constructivist perspective. They can also contribute to related research, in view of the fact that this is a predominant area for the current generations and that the school can not be exempted.
\end{abstract}

Resumo. Este artigo trata-se de um relato de experiência, com viés qualitativo e coleta de dados por meio de observação participante, sobre uma intervenção com crianças do $5^{\circ}$ ano do Ensino Fundamental I. Conhecimentos básicos sobre segurança na internet, ergonomia, hardware, software e acesssibilidade, necessários para uma utilização correta e consciente desse recurso, foram temas analisados. Os resultados apontaram para a importância de os alunos pensarem, descobrirem, articularem teorias e práticas, interpretarem, analisarem e explicarem em palavras como aprender sobre e com computadores, numa perpectiva construtivista. Também podem contribuir com pesquisas afins, tendo em vista tratar-se de uma área predominante para as gerações atuais e da qual a escola não pode se isentar.

\section{Introdução}

Atualmente, os computadores são disponibilizados em muitas escolas de Educação Básica com a prerrogativa de uso como ferramentas de apoio ao ensino e a aprendizagem. No Brasil, apesar de não haver componentes curriculares na Base Nacional Comum Curricular (BNCC), [Brasil 2018] relacionado ao ensino de computação para essa faixa etária, há iniciativas pontuais de projetos desta natureza [Ferri, Santos Rosa 2016] no contexto internacional iniciativas que conduzem a isso. Com a proposição de melhorar o raciocínio lógico dos alunos e aumentar a criatividade na busca por soluções de problemas reais, a Inglaterra modificou seu Currículo da Educação Básica Nacional e, em setembro de 2014, as escolas de Educação Básica começaram a ter profissionais lecionando computação para as crianças [Berry 2013]. No Japão, o ensino de programação já está inserido na disciplina de matemática, da Educação Básica. Alunos com 5 anos de idade começam suas primeiras atividades como desenvolvedores de 
VII Congresso Brasileiro de Informática na Educação (CBIE 2018)

Anais do XXIV Workshop de Informática na Escola (WIE 2018)

programação para computador [Souza et al. 2010]. Em Israel, no Canadá e em Portugal, há evidências dessa inserção curricular [Souza e Passos 2015; Horta, Mendonça e Nascimento 2012], onde, mais especificamente, o modelo de currículo chama a atenção para conteúdos que conduzam ao desenvolvimento do Pensamento Computacional [CSTA 2017].

Questões sobre como os computadores funcionam, como utilizá-los de forma segura, como não prejudicar a saúde ao utilizá-los e como destinar o lixo eletrônico que produzimos, também precisam ser discutidas nos cotidianos escolares. Diante desse contexto, podemos nos perguntar: por que a computação não é uma parte regular do currículo em todas as escolas? Por que tantas escolas não se aproximam do ensino de computação, haja vista que seu uso nos cotidianos cresce aceleradamente? Por que esse tipo de ensino não é adotado por todos como uma grande oportunidade para transformar a Educação Básica e estabelecer nas crianças, a partir de recursos do tempo delas, o interesse e o engajamento nos estudos?

A partir do panorama apresentado, realizamos uma intervenção com crianças matriculadas no $5^{\circ}$ ano do Ensino Fundamental I, por meio da qual trabalhamos 5 tópicos básicos da Ciência da Computação importantes de serem ensinados na Educação Básica. Nossa ênfase consistiu no uso crítico, consciente e criativo de tecnologias computacionais. Entre as lições importantes desse campo, destacamos a construção de conhecimentos básicos de como os computadores são construídos, como funcionam e quais são suas limitações.

Conjecturamos que toda criança (em idade escolar) deva estar ciente das potencialidades dos sistemas de computação e das diferentes possibilidades de falha e uso indevido. Partimos do pressuposto de que o ensino de computação possa apoiar a construção de significados pela criança e elevar seu nível de aprendizagem. Nosso intento é contribuir para uma mudança sistêmica, não por meio de avanços tecnológicos radicais, mas pela adoção progressiva de soluções tecnológicas e estratégias didático-pedagógicas inovadoras que, efetivamente, utilizem e explorem tecnologias computacionais já disponíveis, a fim de melhor equipar professores e estudantes das escolas de Educação Básica para os desafios do trabalho e da sociedade ao longo do século XXI.

Fazemos o relato da experiência mencionada neste artigo, no qual discorremos sobre a Ciência da Computação na Educação Básica; expomos os procedimentos metodológicos que nortearam a intervenção; descrevemos as atividades que a constituíram; e apresentamos os resultados sobre os quais estabelecemos a discussão.

\section{Evidências para a Ciência da Computação na Educação básica}

A inovação tecnológica é um dos sinais que marcam e melhor caracterizam o nosso cotidiano. Seus efeitos se fazem sentir, de forma generalizada, em todos os setores da atividade humana, sendo que a escola não é imune a eles. Ao contrário, ela é crescentemente influenciada pela sociedade do conhecimento cujos "costumes sociais" estimulam uma relação inovadora, aberta e transformadora entre a sociedade e a escola [Unesco 2009]. Não obstante, a proliferação dessas tecnologias não é, ao menos no curto prazo, uma alternativa à escola para milhões de crianças e adultos ao redor do planeta, dado que ainda não têm acesso a elas. Além disso, mesmo que todos, efetivamente, tivessem acesso, não existem, hoje, configurações de ensino e aprendizagem que satisfaçam as metas e as obrigações delegadas à escola contemporânea. Assim, estratégias 
VII Congresso Brasileiro de Informática na Educação (CBIE 2018)

Anais do XXIV Workshop de Informática na Escola (WIE 2018)

pedagógicas aliadas a tecnologias computacionais podem ajudar a definir, de maneira transparente e colaborativa, a escola que queremos ou que acompanhe as evoluções tecnológicas e as manifestações culturais, sociais e econômicas contemporâneas.

Estudos revelam que o uso da tecnologia pode conduzir a resultados inferiores ou de mesma proporção aos obtidos sem ela, quando utilizados como meros repositórios de conteúdo [Santos Rosa 2013]. Por outro lado, encontramos melhores resultados em atividades realizadas com uso da tecnologia digital, porém, com novas abordagens didático-pedagógicas as quais não teriam sido possíveis sem tais recursos, materiais e técnicas de uso instrumental e cognitivo. Mas, como podemos garantir que o uso dessas tecnologias possa conduzir a melhores experiências de ensino e de aprendizagem? Pressupomos que a resposta a essa questão resida na integração da pedagogia com o hardware e o software utilizado. Hoje, existem oportunidades notórias para mover a aprendizagem para algo que se concentre nas necessidades contemporâneas que conduzam a uma formação de crianças e jovens ativos e engajados na preparação do seu futuro em um mundo em rápida mutação, com novos desafios e oportunidades.

Experiências com o ensino de computação na Educação Básica tem sido alvo de pesquisas nacionais e internacionais [Cross et al. 2016; Ferri e Santos Rosa 2016; Wing 2006; Csta 2017; Berry 2013; Souza et al. 2010] na busca por melhorias na qualidade do desenvolvimento cognitivo das crianças com foco no desenvolvimento de suas capacidades para resolver problemas simples ou complexos e para desenvolver o raciocínio lógico, entre outras habilidades. Entre os progressos resultantes da inclusão do ensino dessas tecnologias no currículo escolar, destaca-se a área da Ciência da Computação. Nessa perspectiva, tem-se julgado pertinente investigar e propor o ensino de temas dessa área na Educação Básica, focados no desenvolvimento cognitivo. Considera-se necessário que o aluno aprenda sobre computação, e não meramente aprenda a operar um software específico para editar ou desenhar algo, ou seja, que desenvolva habilidades cognitivas mais complexas, bem como aumente seu senso crítico e criativo sobre como, para que e quando utilizar tecnologias computacionais.

Diante da necessidade supramencionada, ao definir os princípios e fundamentos para a Educação no Ensino fundamental em todo país, os Parâmetros Curriculares Nacionais (PCN) destacam que os alunos devem estar preparados para construir conhecimento e desenvolver novas competências "[...] em função de novos saberes que se produzem e demandam um novo tipo de profissional, preparado para poder lidar com novas tecnologias e linguagens, capaz de responder a novos ritmos e processos." [Brasil 2001, p.28]. Complementar aos PCN, o Plano Nacional de Educação (PNE), 2014-2024, destaca estratégias atreladas à tecnologia que podem contribuir para a melhoria do ensino no Brasil. Segundo o documento, faz-se possível: “[...] selecionar, certificar e divulgar tecnologias educacionais para a alfabetização de crianças [...] fomentar $o$ desenvolvimento de tecnologias educacionais e de práticas pedagógicas inovadoras que assegurem a alfabetização e favoreçam a melhoria do fluxo escolar e a aprendizagem dos (as) alunos (as)" [Brasil 2014, p.58].

Sendo assim, surgem novas demandas para a escola. O processo de ensino e aprendizagem dos alunos tem, desde a Educação Básica, a função de garantir condições para que, a partir de instrumentos que the são conferidos, sejam preparados para um processo de educação permanente conforme as demandas da sociedade. 
VII Congresso Brasileiro de Informática na Educação (CBIE 2018)

Anais do XXIV Workshop de Informática na Escola (WIE 2018)

Apesar de se tratar de uma vasta área de pesquisa com potencialidades no âmbito do desenvolvimento científico e tecnológico e tendo em vista que a sociedade moderna está definida e estruturada pela tecnologia, o sistema escolar ainda se encontra distante das demandas da sociedade contemporânea, isto é, isentando-se dessa influência [Chang et al. 2015]. Nesse contexto, a discussão sobre produzir um currículo contendo conteúdos da Ciência da Computação na Educação Básica reflete um avanço no sistema educacional, já que, assim, se estabeleceria um espaço para o desenvolvimento de novas habilidades que, por sua vez, serão, em um futuro muito próximo, demandas para os profissionais, com ampla capacidade para resolver problemas, para simplificar e interpretar, para liderar, para trabalhar em equipe e para adquirir fluência no uso de tecnologias para quaisquer áreas do conhecimento [Scaico et al. 2012].

\section{Procedimentos Metodológicos}

A pesquisa ora apresentada, um relato de experiência, baseia-se em um viés qualitativo. Coletamos dados por meio de observação participante, que consiste em uma "tentativa de colocar o observador e o observado do mesmo lado" [Mann 1970, p. 96]. Por meio de observações sistemáticas e de apontamentos em questionários objetivos e dissertativos, registramos dados relativos à efetividade da intervenção. Desenvolvemos a pesquisa no âmbito do projeto de extensão "Inclusão Digital", vinculado à Universidade Federal do Paraná (UFPR) o qual consiste em levar tecnologia a crianças, jovens e adolescentes em situação de vulnerabilidade social (renda familiar baixa, maus tratos, envolvimento com drogas, entre outros fatores).

Realizamos a pesquisa empírica ( aprovada pelo Comitê de Etica da UFPR ) de março a julho de 2017, no Lar São Francisco de Assis (LSFA), um Centro Assistencial Beneficiente de uma cidade do interior do Paraná, Brasil. Durante a pesquisa, contamos com a participação de 37 crianças entre 10 e 12 anos do $5^{\circ}$ ano do Ensino Fundamental I. A intervenção, realizada por nós, um licenciando e uma licencianda em Computação (autores deste artigo), consistiu em aulas para abordar temas relacionados ao ensino de computação. No total, foram 72 horas de intervenção, distribuídas em 4 horas semanais.

Em cada aula, fizemos registros, em um editor de texto, das ocorrências das aulas, considerando as seguintes questões: $\mathrm{O}$ que funcionou? $\mathrm{O}$ que não funcionou? $\mathrm{O}$ que mais chamou a atenção da criança? Qual foi o maior desafio? O que foi feito para observar se os objetivos da aula foram cumpridos? Quais foram as analogias feitas pelas crianças sobre os componentes em estudo, a partir dos seus conhecimentos prévios?

Para iniciar a pesquisa, desenvolvemos um programa curricular abordando temas relacionadas à informática: ergonomia no uso de computadores, segurança na internet, lixo eletrônico, software, internet (temas relacionados à computação) e hardware (tema interdisciplinar relacionado à computação, química e física).

Passamos a apresentação dos resultados.

\section{Resultados e Discussão}

Durante as atividades, utilizamos uma organização diferenciada de sala de aula a qual teve origem no projeto Hands-on-Tec [Santos Rosa, Rosa e Sales 2014]. Nela, não há carteiras posicionadas em fila, as mesas são redondas com os alunos trabalhando em grupos, a sala possui internet sem fio de alta velocidade, há notebooks e tablets no lugar de cadernos e livros e uma lousa digital substituindo o quadro de giz comum. 
VII Congresso Brasileiro de Informática na Educação (CBIE 2018)

Anais do XXIV Workshop de Informática na Escola (WIE 2018)

Ressaltamos que, no campo educacional, adaptar-se às novas gerações faz parte do processo de inovação e que, atualmente, há uma grande diversidade de alterações que podem ser adotadas para melhorar cada vez mais a educação. Na sala Hands-on-Tec abordamos os temas das aulas e explicamos as atividades, todas realizadas com a utilização dos dispositivos móveis, com recurso a pesquisas na internet, vídeos, jogos educativos e formulários online.

Nas primeiras aulas, constatamos comportamentos inadequados e indisciplinares das crianças. Entretanto, devido ao fato de todas as atividades terem sido planejadas com antecedência, com foco na aproximação com os seu cotidianos [Rosa e Schuhmacher 2009], o rendimento no processo de aprendizagem tornou-se mais rápido e satisfatório.

Passamos ao relato dos resultados alcançados em cada um dos temas definidos $a$ priori: ergonomia no uso de computadores, segurança na internet, lixo eletrônico, software, internet e hardware. Para tanto, apresentamos, nos Quadros de 1 a 5, uma definição de cada tema e respostas às seguintes perguntas, já mencionadas: $O$ que funcionou? O que não funcionou? O que chamou mais atenção da criança? Qual foi o maior desafio? O que foi feito para observar se os objetivos da aula foram cumpridos? Analogias relacionadas ao conhecimento prévio das crianças.

\subsection{Ergonomia no uso de computadores}

Neste item, explicamos a importância de uma postura correta ao utilizar dispositivos tecnológicos. No Quadro 1, encontra-se uma síntese dos resultados e da discussão relacionados à ergonomia no uso de computadores.

\section{Quadro 1: Resultados da aula de Ergonomia no uso de computadores}

\begin{tabular}{|c|c|}
\hline O que funcionou? & $\begin{array}{l}\text { Os exercícios práticos que foram exercutados, tanto de alongamento } \\
\text { quanto durante a aula, na correção da postura dos alunos. }\end{array}$ \\
\hline O que não funcionou? & $\begin{array}{l}\text { Não possuíamos recursos para abordar o tema postura ao utilizar o } \\
\text { computador e para realizar demonstrações sobre a altura necessária de } \\
\text { mesas e cadeiras e também do monitor, teclado e mouse. }\end{array}$ \\
\hline $\begin{array}{l}\text { O que chamou mais atenção da } \\
\text { criança? }\end{array}$ & $\begin{array}{l}\text { Os exercícios de aquecimento - que despertaram muito interesse na } \\
\text { participação das crianças - e também alguns vídeos de animação com } \\
\text { humor que não só retratavam a realidade da falta de ergonomia em } \\
\text { alguns locais, como também corrigiam essa falta de ergonomia. }\end{array}$ \\
\hline Qual foi o maior desafio? & $\begin{array}{l}\text { Houve dificuldade em encontrar conteúdo relacionado à computação, } \\
\text { além de que alguns conteúdos teóricos sobre o tema não despertaram o } \\
\text { interesse dos alunos. }\end{array}$ \\
\hline $\begin{array}{l}\text { O que foi feito para observar se } \\
\text { os objetivos da aula foram } \\
\text { cumpridos? }\end{array}$ & $\begin{array}{l}\text { Observamos, no final da aula sobre ergonomia, se os alunos corrigiram } \\
\text { sua postura após terem visto a maneira correta de sentar-se. } \\
\text { Igualmente, aplicamos formulários com perguntas relacionadas ao } \\
\text { conteúdo exposto em aula. }\end{array}$ \\
\hline $\begin{array}{l}\text { Analogias relacionadas ao } \\
\text { conhecimento prévio das } \\
\text { crianças }\end{array}$ & $\begin{array}{l}\text { Mostramos imagens de posturas incorretas de pessoas utilizando } \\
\text { dispositivos eletrônicos, e as crianças foram relacionando com } \\
\text { posturas que elas mesmas praticavam sem saber que estavam erradas. }\end{array}$ \\
\hline
\end{tabular}

\subsection{Segurança na Internet}


VII Congresso Brasileiro de Informática na Educação (CBIE 2018)

Anais do XXIV Workshop de Informática na Escola (WIE 2018)

No tema de Segurança na Internet, utilizamos materiais de apoio, tais como filmes e vídeos sobre o assunto. Realizamos atividades práticas e aplicamos formulários com questões para a fixação do conhecimento das crianças. No Quadro 2, encontram-se os resultados.

\section{Quadro 2: Resultados da aula de Segurança na internet}

\begin{tabular}{|l|l|}
\hline $\begin{array}{l}\text { Definição de Segurança na Internet: É responsável pela criação de métodos, procedimentos e normas que } \\
\text { buscam identificar e eliminar as vulnerabilidades das informações e equipamentos físicos, como os } \\
\text { computadores. [Cortez, Kubota 2013]. }\end{array}$ \\
\hline O que funcionou? & $\begin{array}{l}\text { As crianças, todas menores de idade com redes sociais, não possuíam } \\
\text { tipo algum de ciência sobre o tema . Como os pais, na maioria das vezes, } \\
\text { não alertam sobre ameaças, foi uma aula muito interesssante para as } \\
\text { crianças. }\end{array}$ \\
\hline O que não funcionou? & $\begin{array}{l}\text { Como as crianças são menores de idade, por motivos de restrições de } \\
\text { privacidade, não pudemos criar contas e senhas nem expor medidas de } \\
\text { segurança em redes sociais para elas. }\end{array}$ \\
\hline $\begin{array}{l}\text { O que chamou mais atenção } \\
\text { da criança? }\end{array}$ & $\begin{array}{l}\text { Os dados, as estatísticas e os relatos de situações em que medidas de } \\
\text { segurança na internet não foram tomadas, roubo de dados e infecção dos } \\
\text { dispositivos com possíveis malwares. }\end{array}$ \\
\hline $\begin{array}{l}\text { Qual foi o maior desafio? } \\
\text { O que foi feito para observar } \\
\text { se os objetivos da aula foram } \\
\text { cumpridos? }\end{array}$ & $\begin{array}{l}\text { Realizamos uma atividade com o intuito de verificar, por exemplo, quais } \\
\text { eram os níveis de segurança das senhas que as crianças usaram e quais } \\
\text { são as informações divulgadas por elas em suas redes sociais. }\end{array}$ \\
\hline $\begin{array}{l}\text { Analogias relacionadas ao } \\
\text { conhecimento prévio das } \\
\text { crianças }\end{array}$ & $\begin{array}{l}\text { Relatos das crianças sobre notícias relacionadas ao tema foram } \\
\text { mencionadas durante a aula sobre segurança na internet. Alguns até } \\
\text { relataram quais foram as consequências para essas pessoas. }\end{array}$ \\
\hline
\end{tabular}

\subsection{Hardware}

Nessa aula, apresentamos vídeos sobre as peças dos computadores e entregamos às crianças gabinetes de computadores para que elas os desmontassem, peça por peça. A partir disso, utilizamos o Hard Disc (HD), reproduzimos a atividade "furacão de HD" [Manual do Mundo 2012] e trabalhamos conceitos computacionais e de química e física. Ao tratarmos dos periféricos dos computadores, abordamos os componentes gerais com estudo de vídeos, pesquisas online e formulários. No Quadro 3, apresentamos os resultados relacionados a esse tema.

\section{Quadro 3: Registros da aula sobre Hardware}

\begin{tabular}{|l|l|}
\hline $\begin{array}{l}\text { Definição de hardwere: É a parte física de um computador; é formado pelos componentes eletrônicos } \\
\text { [Keen 1996]. }\end{array}$ & $\begin{array}{l}\text { As atividades práticas que foram propostas para as crianças, como a } \\
\text { desmontagem e montagem de um computador, cujo objetivo era } \\
\text { descrever as peças e suas funções. }\end{array}$ \\
\hline O que funcionou? & $\begin{array}{l}\text { Algumas crianças se mostravam distantes do objetivo da aula, o que pode } \\
\text { ter ocorrido por haver uma uma grande quantidade de crianças e poucos } \\
\text { computadores. }\end{array}$ \\
\hline O que não funcionou? & $\begin{array}{l}\text { A integração com a tecnologia nas atividades durante a aula. Isso causou } \\
\text { grande estímulo nas crianças para a realização das atividades. }\end{array}$ \\
\hline $\begin{array}{l}\text { O que chamou mais atençãa } \\
\text { da criança? }\end{array}$
\end{tabular}


VII Congresso Brasileiro de Informática na Educação (CBIE 2018)

Anais do XXIV Workshop de Informática na Escola (WIE 2018)

\begin{tabular}{|l|l|} 
Qual foi o maior desafio? & $\begin{array}{l}\text { O tema hardware possui muitos nomes e assuntos complexos para se } \\
\text { explicar para uma criança. }\end{array}$ \\
\hline $\begin{array}{l}\text { O que foi feito para observar } \\
\text { se os objetivos da aula foram } \\
\text { cumpridos? }\end{array}$ & $\begin{array}{l}\text { Durante a remontagem do computador, solicitamos a descrição das peças } \\
\text { e sua função no computador. Nesse momento, verificamos o nível de } \\
\text { aprendizagem das crianças sobre esse assunto. }\end{array}$ \\
\hline $\begin{array}{l}\text { Analogias relacionadas ao } \\
\text { conhecimento prévio das } \\
\text { crianças }\end{array}$ & $\begin{array}{l}\text { Durante a apresentação das peças do computador, as crianças } \\
\text { relacionaram, por exemplo, uma placa-mãe a uma cidade e o processador, } \\
\text { a um cérebro. }\end{array}$ \\
\hline
\end{tabular}

Durante a aula sobre hardware, observamos que, nas atividades práticas, as crianças participavam diretamente quando interagiam com o conteúdo e com o material de apoio proposto, momentos nos quais as crianças se apropriaram em conjunto com outros colegas e, didaticamente, com o professor. Como possuíamos uma quantidade limitada de computadores para as crianças realizarem a atividade prática, notamos uma dificuldade de alguns participarem ativamente do processo de montagem e desmontagem. Como consequência, algumas se mostraram desmotivadas para continuar a atividade. A solução foi a divisão e o revezamento nas funções. Em momentos diferentes, as crianças se revezaram entre a montagem e a descrição das peças que foi utilizada como uma forma de avaliar o conhecimento construído.

\subsection{Lixo eletrônico}

Já no tema de Lixo Eletrônico, discutimos, quais os danos que podem causar ao descartamos aparelhos eletrônicos em lugares não apropriados e o que os componentes químicos presentes nesses equipamentos podem causar ao meio ambiente. $\mathrm{O}$ resultado encontra-se no quadro 4 :

\section{Quadro 4: Registros da aula de Lixo Eletrônico}

\begin{tabular}{|l|l|}
\hline $\begin{array}{l}\text { Definição de Lixo Eletrônico: É focado no descarte de eletrônicos sem utilidade. Este descarte é feito } \\
\text { quando o equipamento apresenta defeito ou torna-se muito antiquado [Inatel 2018] }\end{array}$ \\
\hline O que funcionou? & $\begin{array}{l}\text { O conhecimento prévio dos alunos em relação ao conteúdo da aula } \\
\text { e os formulários. }\end{array}$ \\
\hline O que não funcionou? & $\begin{array}{l}\text { Na turma da manhã, encontramos muitas dificuldades em relação ao } \\
\text { comportamento dos alunos (nas apresentações de slides, eles ficam } \\
\text { um pouco dispersos). }\end{array}$ \\
\hline $\begin{array}{l}\text { O que chamou mais atenção da } \\
\text { criança? }\end{array}$ & $\begin{array}{l}\text { As imagens dos equipamentos reutilizados que mostramos na aula. } \\
\text { elação dos alunos ao se depararem com algo desconhecido por }\end{array}$ \\
\hline $\begin{array}{l}\text { Qual foi o maior desafio? } \\
\text { elapocupante ao meio ambiente. }\end{array}$ & $\begin{array}{l}\text { A maior dificuldade foi a tentar explicar o conteúdo para uma aluna } \\
\text { especial que tem dificuldade em ler e em interagir com os demais } \\
\text { alunos da sala. }\end{array}$ \\
\hline $\begin{array}{l}\text { O que foi feito para observar se os } \\
\text { objetivos da aula foram } \\
\text { cumpridos? }\end{array}$ & $\begin{array}{l}\text { Efetuamos a avaliação do conhecimento por meio de formulários } \\
\text { online e projetos com iniciativas para reutilização do lixo eletrônico. }\end{array}$ \\
\hline $\begin{array}{l}\text { Analogias relacionadas ao as } \\
\text { conhecimento prévio das crianças }\end{array}$ & $\begin{array}{l}\text { Os alunos relataram as inúmeras vezes em que presenciaram lixo } \\
\text { eletrônico sendo descartado em locais na cidade. }\end{array}$ \\
\hline
\end{tabular}

Quanto ao tema Software, ressaltamos informações básicas sobre o assunto, utilizando aplicativos instalados nos tablets e ultrabooks. Nessa aula, diferente das demais, as crianças foram ao laboratório de informática da UFPR onde cada uma teve seu próprio computador. Utilizaram o software Wordpad e o Google Drive e, a partir dos 
VII Congresso Brasileiro de Informática na Educação (CBIE 2018)

Anais do XXIV Workshop de Informática na Escola (WIE 2018)

registros feitos por eles por meio dessas ferramentas, foi possível observar suas escritas e o seus raciocínios lógicos. No quadro 5, apresentamos os resultados dessa intervenção.

\section{Quadro 5: Registros da aula de Software}

\begin{tabular}{|l|l|}
\hline $\begin{array}{l}\text { Definição de Software: Sequência de instruções escritas para serem interpretadas por um computador } \\
\text { [Pressman 2016]. }\end{array}$ & $\begin{array}{l}\text { Uma visita ao laboratório de informática da UFPR para fazer o uso } \\
\text { dos computadores. As crianças se mostraram interessadas no novo } \\
\text { local da aula e engajadas nas atividades. }\end{array}$ \\
\hline O que funcionou? & $\begin{array}{l}\text { As crianças sempre se atrasavam um pouco para chegar à } \\
\text { universidade e precisavam sair mais cedo por causa do ônibus. } \\
\text { Consequentemente, o tempo de aula ficou reduzido. }\end{array}$ \\
\hline $\begin{array}{l}\text { O que chamou mais atenção da funcionou? } \\
\text { criança? }\end{array}$ & $\begin{array}{l}\text { Pela primeira vez, cada criança possuía seu próprio computador } \\
\text { para realizar as atividades. }\end{array}$ \\
\hline $\begin{array}{l}\text { Qual foi o maior desafio? } \\
\text { Como cada criança possuía um computador, nós (licenciandos) } \\
\text { precisávamos, frequentemente, observar se as crianças estavam } \\
\text { acessando conteúdos que não coincidiam com o assunto abordado } \\
\text { na aula. }\end{array}$ \\
\hline $\begin{array}{l}\text { O que foi feito para observar se os } \\
\text { objetivos da aula foram cumpridos? }\end{array}$ & $\begin{array}{l}\text { Organizamos grupos, e cada grupo apresentou uma atividade sobre } \\
\text { o tema que lhe foi destinado. }\end{array}$ \\
\hline $\begin{array}{l}\text { Analogias relacionadas } \\
\text { conhecimento prévio das crianças }\end{array}$ & $\begin{array}{l}\text { As crianças relacionaram os endereços dos sites da internet com os } \\
\text { endereços comuns nas casas. }\end{array}$ \\
\hline
\end{tabular}

Para verificar o nível de aprendizagem das crianças, organizamos grupos de 4 integrantes, sendo que cada um recebeu a incumbência de elaborar uma apresentação sobre um dos tópicos relacionados ao tema propostos por nós. Filmamos as apresentações e as apresentamos em um blog. Assim, os colegas da aula poderiam comentar a respeito das apresentações. Essa atividade também trabalhou a oralidade das crianças. Constatamos que recursos multimídia, usados como ferramenta cognitiva [Jonsassen 2007], são úteis para manter a atenção do aluno no conteúdo e, então, procuramos utilizar sempre vídeos e promover debates para que as crianças se expressassem sobre o que haviam aprendido. Constatamos, igualmente, que slides com muito texto provocavam desinteresse nelas.

Nos quadros apresentados ao longo desta seção, constam um item relacionado às analogias feitas pelas crianças durante as atividades. Rosa e Schuhmacher [2008] nos ensinam que, segundo a aprendizagem significativa, quanto mais sabemos, mais aprendemos e que a aprendizagem é facilitada quando há uma relação entre o que sabemos e um novo conhecimento. Durante nossa intervenção, constatamos que as crianças entendem com maior facilidade caso haja algum relacionamento entre $o$ conteúdo proposto e algo que acontece em seus cotidianos. Dois exemplos que percebemos durante as aulas estão descritos no Quadro 5: se referem a relações que as crianças fizeram com seu conhecimento prévio na aula sobre software.

Procuramos, em todas as aulas, desenvolver atividades, voltadas ao uso de computadores como ferramentas cognitivas [Jonassen 2007] que envolvessem as crianças. Na maior parte delas, aplicamos formulários. No blog que criamos, constatamos relatos como este: "adorei muito bom eu me diverti muitoooooo" $\mathrm{e}$ "adorei a melhor aula do mundo!". Isso permite inferir o quanto elas gostaram das aulas e afirmar o quanto nos davam motivação para continuar. 
VII Congresso Brasileiro de Informática na Educação (CBIE 2018)

Anais do XXIV Workshop de Informática na Escola (WIE 2018)

Assim como Ferri e Santos Rosa (2016), percebemos que a integração da tecnologia com o ensino de computação conduz a um grande estímulo para as crianças. Elas se sentem motivadas. São recursos de multiuso que trazem grandes possibilidades para potencializar os processos de ensino e de aprendizagem.

\section{Considerações Finais}

Ao longo deste artigo apresentamos um relato de experiência com argumentos para introduzir o currículo de Ciência da Computação nas escolas de Ensino Fundamental I. Os resultados apontaram para a importância de os alunos passarem a maior parte do tempo pensando, descobrindo, articulando teorias e práticas, interpretando, analisando e explicando em palavras como aprender sobre computadores e com computadores, numa perspectiva construtivista. Constatamos que as crianças desenvolveram senso crítico sobre os danos causados à sua saúde (ergonomia), a sua segurança e danos causados ao meio ambiente (lixo eltrônico). Tais avaliações, ao serem desenvolvidas por pares ou em grupos, apresentaram discussões e pontos de vista sob várias perspectivas, além de que as atividades remeteram à aprendizagem colaborativa e crítica. $\mathrm{O}$ objetivo principal é ensinar às crianças um novo conjunto de habilidades relacionadas à principal tecnologia do tempo atual (século XXI). A viabilidade da inclusão do ensino da computação é um tema que requer muita discussão e trabalho colaborativo. Pesquisa de mesma natureza da apresentada neste artigo abre novas oportunidades para contribuir com melhorias na qualidade da Educação Básica brasileira e, consequentemente, com o futuro da sociedade.

\section{Referências}

Abergo. (2018). Ergonomia. Disponível em: http://www.abergo.org.br/internas.php?pg=o_que_e_ergonomia $>$. Acesso em: 29 Jun.

Berry, M. (2013). Computing in the national curriculum: a guide for primary teacher. Newnorth Print, Ltd. Bedford. 2013. Disponível em: http://www.computingatschool.org.uk/data/uploads/CASPrimaryComputing.pdf. Acessado em 12/03/2018.

BRASIL. Ministério da Educação. Governo Federal. Base Nacional Curricular. Disponível em: http://basenacionalcomum.mec.gov.br/download-da-bncc. Acessado em: $12 / 03 / 2018$.

Brasil. (2014). Plano Nacional de Educação 2014-2024 [recurso eletrônico] : Lei n $^{\text {o }}$ 13.005, de 25 de junho de 2014. Brasília : Câmara dos Deputados, Edições Câmara.

Chang, S.; De Paula, R.; Tostes, A. M. B.; Barbosa, G. S. (2015). Uma Investigação sobre o Uso de Ferramentas Computacionais no Ensino de Cálculo Integral e Diferencial. Renote - Revista Novas Tecnologias na Educação. n. 2010. v. 13, n. 2.

Cortez, I.S., Kubota, L.C. (2013). Contramedidas em segurança da informação e vulnerabilidade cibernética: evidência empírica de empresas brasileiras. R.Adm., São Paulo, v.48, n.4, p.757-769.

Cross, J., Hamner, E., Zito, L. \& Nourbakhsh, I. (2016). Engineering and Computational Thinking Talent in Middle School Students : a Framework for Defining and Recognizing Student Affinities. 
VII Congresso Brasileiro de Informática na Educação (CBIE 2018)

Anais do XXIV Workshop de Informática na Escola (WIE 2018)

CSTA. Computer Science Teacher Association. (2005). The New Educational Imperative: Improving High School Computer Science Education. ACM - Association for Computing Machinery.

Ferri, J., Santos Rosa, S. (2016). Como o Ensino de Programação de Computadores Pode Contribuir Com a Construção de Conhecimento na Educação Básica Uma Revisão Sistemática da Literatura. Revista Renote, Porto Alegre, v. 2, n. 14, p.1-10.

Inatel. Lixo Eletrônico. (2018). Disponível em: <http://www.inatel.br/lixoeletronico/>. Acesso em: 29 jun. 2018.

Jonassen, D. (2007). Computadores, ferramentas cognitivas. Porto: Porto Editora.

Keen, P. G. W. (1996). Guia gerencial para a tecnologia da informação: conceitos essenciais e terminologia para empresas e gerentes. Rio de Janeiro: Campus.

Mann, P. H. (1970). Métodos de investigação sociológicas. Rio de Janeiro: Zahar, 1970.

Manual do Mundo. (2012). Furacão de água com HD. Disponível em : http://www.manualdomundo.com.br/2012/12/furacao-de-agua-vortex-agitadormagnetico/. Acessado em 01 de fev. de 2018.

Pressman, R. Maxim, B. (2016). Engenharia de Software. Bookman, 8a Edição Uma Abordagem Profissional.

Rosa V., Schuhmacher, E. (2009). Construção de gráficos de setores por alunos portadores de deficiência visual In: I Simpósio Nacional de Ensino de Ciência e Tecnologia, v.1. p.745 - 754 .

Santos Rosa, S. (2013). A influência das tdic na (re)configuração de modelos de ead tradicionais para educação online. Renote. V. 11 N$^{0} 3$, dezembro.

Santos Rosa, S., Rosa, V., Sales, M. B. (2014). Portal virtual hands-on-tec: recurso de autoria para professores da educação básica. Multimedia Journal of Research in Education, v.1, p.1 - 6 .

Scaico, P. D. ; Henrique, M. S.; Cunha, F. O. M.; Alencar, Y. M. (2012). Um Relato de Experiências de Estagiários da Licenciatura em Computação com o Ensino de Computação para Crianças. Renote. V. 10 n. 3.

Sousa, R. V.; Barreto L. P; Andrade, A; Abdalla, D. (2010). Ensinando e aprendendo conceitos sobre a ciência da computação sem o uso do computador: Computação Unplugged!. Práticas em Informática na Educação: Minicursos do Congresso Brasileiro de Informática na Educação, vol. 1, Número 1.

Unesco. (2009). Organização das Nações Unidas para a Educação, a ciência e a cultura. Educação e aprendizagem para todos: olhares dos cinco continentes. - Brasília: Ministério da Educação.

Wing, J.M. (2006). Computational Thinking. It represents a universally applicable attitude and skill set everyone, not just computer scientists, would be eager to learn and use. Communications Of The Acm. Vol. 49, No. 3. 